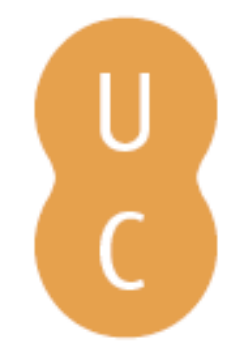

\title{
nommalina
}

\section{A produção desigual do espaço como geradora de temperaturas extremas em cidades médias tropicais: o exemplo de São Carlos/SP Brasil}
Autor(es):
Rampazzo, Camila Riboli; Sant'Anna Neto, João Lima
Publicado por: Imprensa da Universidade de Coimbra; RISCOS - Associação
Portuguesa de Riscos, Prevenção e Segurança
persistente:
URI:http://hdl.handle.net/10316.2/34954
DOI:
DOl:http://dx.doi.org/10.14195/978-989-96253-3-4_154
Accessed : $\quad$ 26-Apr-2023 12:13:25

A navegação consulta e descarregamento dos títulos inseridos nas Bibliotecas Digitais UC Digitalis, UC Pombalina e UC Impactum, pressupõem a aceitação plena e sem reservas dos Termos e Condições de Uso destas Bibliotecas Digitais, disponíveis em https://digitalis.uc.pt/pt-pt/termos.

Conforme exposto nos referidos Termos e Condições de Uso, o descarregamento de títulos de acesso restrito requer uma licença válida de autorização devendo o utilizador aceder ao(s) documento(s) a partir de um endereço de IP da instituição detentora da supramencionada licença.

Ao utilizador é apenas permitido o descarregamento para uso pessoal, pelo que o emprego do(s) título(s) descarregado(s) para outro fim, designadamente comercial, carece de autorização do respetivo autor ou editor da obra.

Na medida em que todas as obras da UC Digitalis se encontram protegidas pelo Código do Direito de Autor e Direitos Conexos e demais legislação aplicável, toda a cópia, parcial ou total, deste documento, nos casos em que é legalmente admitida, deverá conter ou fazer-se acompanhar por este aviso.

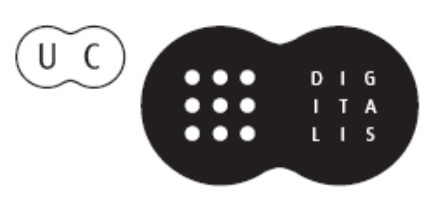



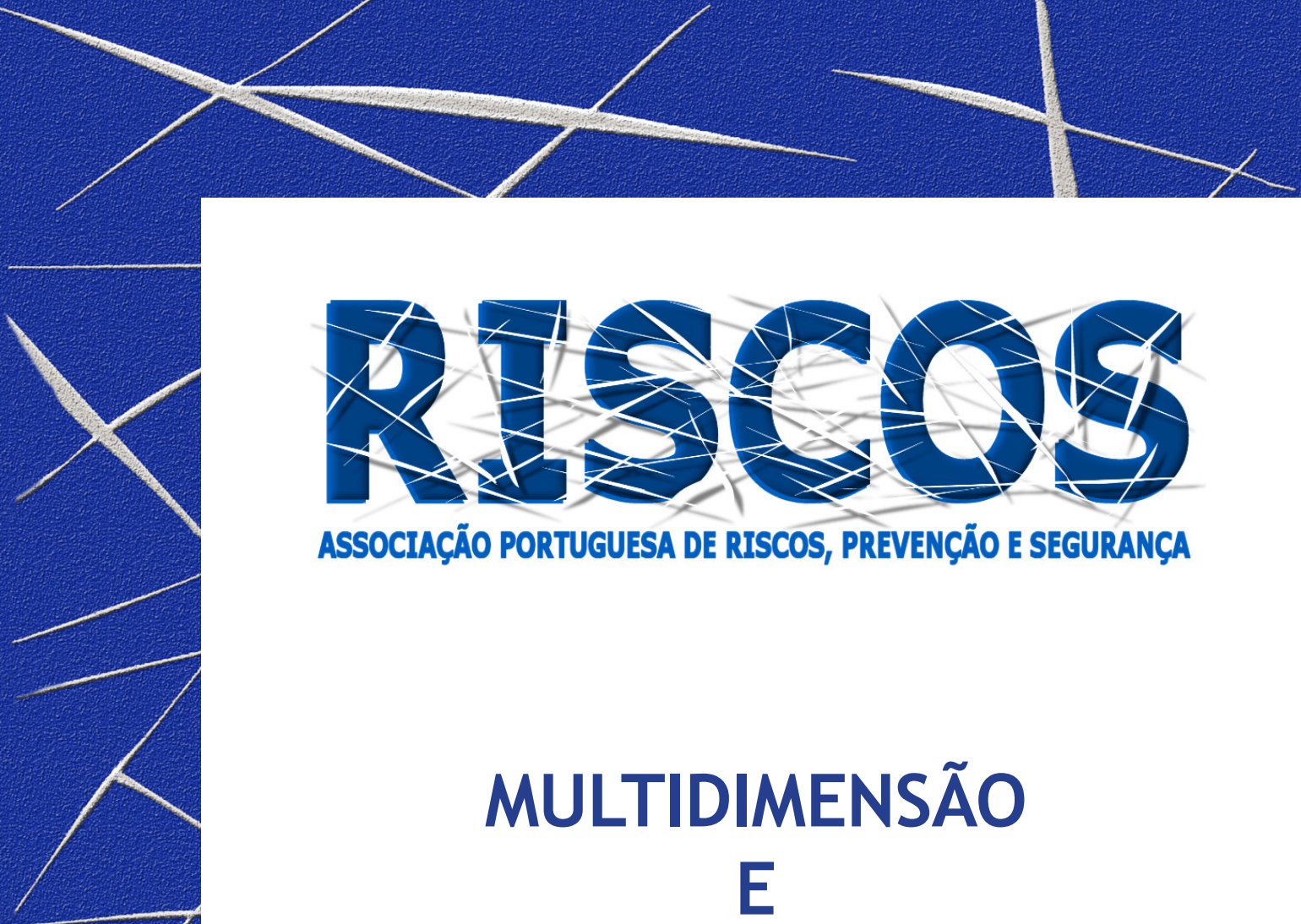

ASSOCIAÇÃO PORTUGUESA DE RISCOS, PREVENCCÃO E SEGURANÇA

MULTIDIMENSÃO

E
TERRITÓRIOS DE RISCO

III Congresso Internacional

I Simpósio Ibero-Americano

VIII Encontro Nacional de Riscos

Guimarães

2014 


\title{
A PRODUÇÃO DESIGUAL DO ESPAÇO COMO GERADORA DE TEMPERATURAS EXTREMAS EM CIDADES MÉDIAS TROPICAIS: O EXEMPLO DE SÃO CARLOS/SP BRASIL
}

\author{
Camila Riboli Rampazzo \\ Grupo de Pesquisa GAIA; FCT/UNESP Presidente Prudente \\ camila.rampazzo@hotmail.com \\ João Lima Sant'Anna Neto \\ Departamento de Geografia, Grupo de Pesquisa GAIA; FCT/UNESP Presidente Prudente. \\ jlsn57@uol.com.br
}

\begin{abstract}
RESUMO
Em relação aos problemas ambientais urbanos, principalmente aqueles associados ao clima, é importante aprofundar o referencial para identificar a gênese dos processos que desencadeiam a distribuição desigual de calor em áreas urbanas tropicais tendo como ponto de partida a dinâmica de produção desigual dos espaços como geradora de temperaturas extremas nas cidades. Desta forma, o presente estudo objetiva analisar a dinâmica de produção do espaço de São Carlos/SP (uma cidade média tropical de altitude) para identificar processos que permitam considerar que o elemento natural clima também é um agente que pode reforçar ou atenuar as desigualdades. Para isso, além de uma análise geográfica, o trabalho identifica a ocorrência e distribuição espacial das diferenças de temperatura em espaços com distintos padrões de ocupação/ edificação, vegetação e o espaço rural próximo. Os resultados mostram diferenças de até $5,3^{\circ} \mathrm{C}$ refletindo a relação entre a produção desigual do espaço na geração de temperaturas extremas.

Palavras-chave: produção do espaço, cidades médias, temperatura extrema, clima urbano, São Carlos/Brasil
\end{abstract}

\section{Introdução}

A forma com que os espaços urbanos têm sido produzidos (resultado de um complexo processo de atuação e intervenção dos agentes sociais sob uma paisagem em constante mutação) acaba por potencializar ou amenizar as dinâmicas de geração de condições mais ou menos adequadas ao conforto ambiental, importante indicador da qualidade de vida no espaço urbano.

As cidades, enquanto projeções construídas artificiais no espaço (MONTEIRO, 1997) passam a refletir essas alterações e condições de desconforto a partir do resultado cumulativo de modificações na cobertura do solo e substituição de objetos naturais por materiais construtivos inadequados, contribuindo para o armazenamento de calor e aumento extremo da temperatura do ar quando da sua liberação, ainda que na ausência da radiação solar (AMORIM, 2011, p.134); (LOPES, 2009, p.41). Desta forma, o objetivo do artigo é desenvolver uma análise do processo de produção desigual do espaço urbano de São Carlos/SP (uma cidade média do ambiente tropical) para identificar os processos e o contexto urbano de geração de temperaturas extremas que permitam considerar que o elemento natural clima também é um agente que pode reforçar ou atenuar as desigualdades sociais (SANT’ANNA NETO, 2012, p.220). Para isso, é identificada a ocorrência e a distribuição espacial das diferenças de temperatura em espaços com distintos padrões de ocupação/edificação, vegetação.

Clima e a produção desigual do espaço urbano: diferenciação socioespacial e a construção social do clima - especificidades de São Carlos/SP Brasil

A importância em estudar as dinâmicas climáticas, em qualquer dimensão do ambiente urbano é que tais estudos têm oferecido importantes subsídios ao planejamento e melhoria da qualidade do ambiente das cidades. Segundo Fernández García, Rasilla Álvarez (2008, p.513) “La ciudad 
no es un espacio homogéneo y lo que denominamos genéricamente como clima urbano presenta gran cantidad de matices asociados a la morfología de los edificios, el trazado de las calles y la presencia de zonas verdes".

A cidade de São Carlos, localizada nas coordenadas geográficas $21^{\circ} 30^{\prime}$ e $22^{\circ} 30^{\prime}$ de latitude Sul e $47^{\circ} 30^{\prime}$ e $48^{\circ} 30^{\prime}$ de longitude Oeste, a $856 \mathrm{~m}$ de altitude, segundo Lima (2007, p.87) passou por períodos intensos de expansão territorial desde 1857 cujo processo de produção do espaço também configurou situações de segregação socioespacial imposta a diferenciação socioespacial (CARLOS, 2007, p.48), territorializando morfologias urbanas distintas (VILAGRASA, 1991). A partir daí ampliaram-se os eixos de expansão junto à Rodovia Washington Luís já com traços de descontinuidade rumo à periferia e criação de loteamentos fechados e periféricos em relação à malha urbana com novos padrões urbanísticos irregulares carentes de infraestrutura, com tendência a verticalização e periferização, sobretudo em 1997.

Para esta análise, parte-se de dois recortes distintos. Um é o bairro Vila Elizabeth na área Norte criado em 1949, e que foi um dos principais destinos das famílias de alta renda que deixavam o centro da cidade devido ao aumento de estabelecimentos comerciais. Outro recorte é o bairro Cidade Aracy na área Sul criado em 1982, e segundo Plano Local de Habitação de Interesse Social de São Carlos (2010) é a região do município com maior concentração de situações de precariedade, pobreza, vulnerabilidade social e, além destas, situar-se em área de preservação permanente. Desta forma, segundo Sant'Anna Neto (2011) é preciso considerar que a maneira que o elemento natural clima impacta os diferentes segmentos sociais se dá de forma distinta de acordo com o lugar que ocupam na estrutura urbana.

\section{Procedimentos metodológicos}

Tendo por objetivo identificar a forma de ocorrência de diferenças de temperatura em cidades de diferentes portes, foi utilizada a metodologia dos transectos móveis a fim de identificar as características térmicas do clima urbano.

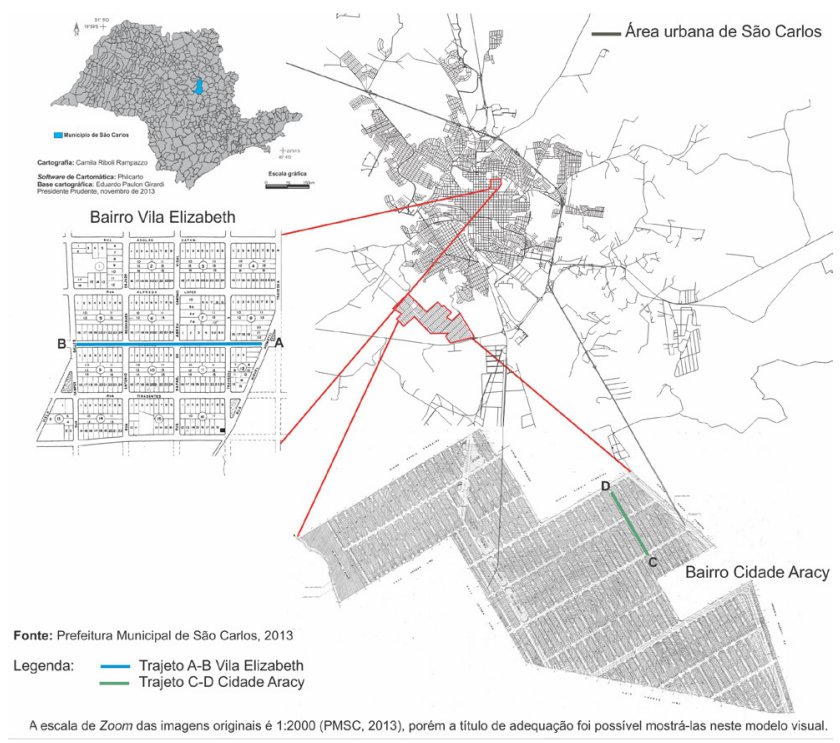

Figura 1. Trajetos A-B e C-D em São Carlos. 
O transecto móvel consiste no registro da temperatura do ar em movimento contínuo. 0 levantamento foi feito nos bairros Vila Elizabeth e Cidade Aracy (Figura 1 acima), com sensores digitais em veículos a 1,5m do chão, nos horários das 15hrs e 18hrs no dia 13/12/2013 enquanto um dia típico de verão. Os dados foram articulados aos perfis longitudinais elaborados no software CorelDRAW®.

\section{Resultados e discussão}

Em relação aos aspectos geoambientais a Vila Elizabeth mostra homogeneidade nas funções e usos, predominantemente residencial com padrão construtivo médio/alto de edificações em lotes amplos e vegetação de médio e grande porte (Figura 2).
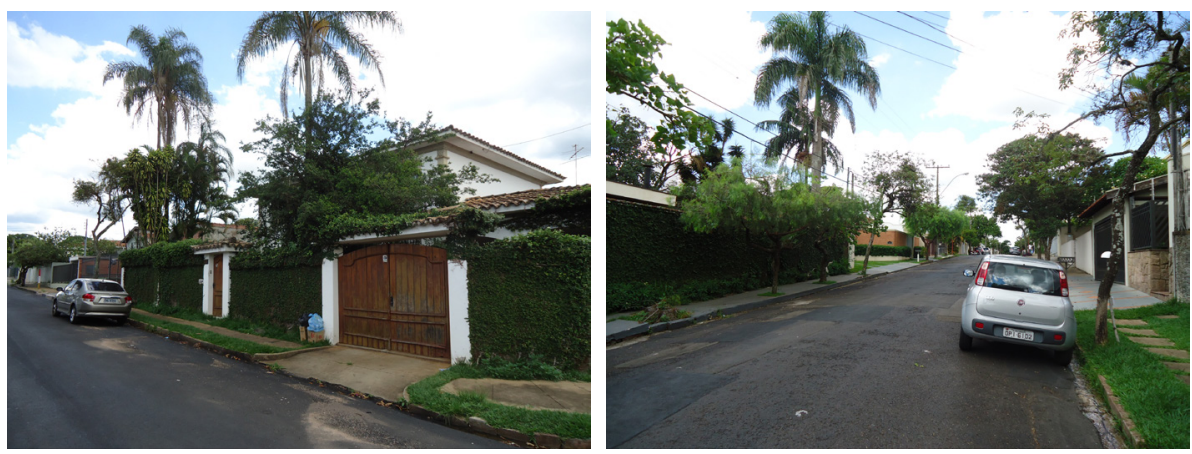

Figura 2: Vista parcial das características dos pontos do trajeto A-B Vila Elisabeth.

Com relação ao bairro Cidade Aracy (Figura 3) observa-se que a vegetação é predominante de pequeno porte ou ausente. 0 material construtivo é em sua maioria alvenaria com telhado do tipo fibrocimento, laje e cerâmica, uso residencial e comércio local. A dimensão dos lotes é pequena, edificações de sobrados, geminadas ou edículas.
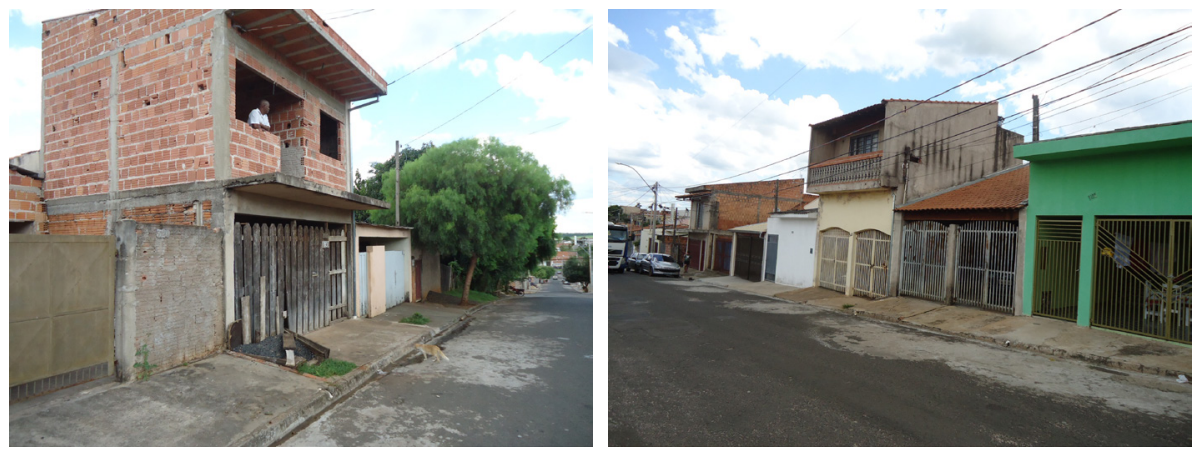

Figura 3: Vista parcial das características dos pontos do trajeto C-D Cidade Aracy.

Com base nos dados de temperatura foram gerados os perfis longitudinais na Figura 4, e em medições diurnas a diferença máxima de temperatura foi $3,8^{\circ} \mathrm{C}$. Observa-se que no mesmo horário a temperatura do ar no bairro Vila Elizabeth foi inferior. 0 ponto 1 na Vila Elizabeth apresentou menor temperatura $\left(28,0^{\circ} \mathrm{C}\right)$, e o ponto 2 na Cidade Aracy apresentou $31,8^{\circ} \mathrm{C}$. 


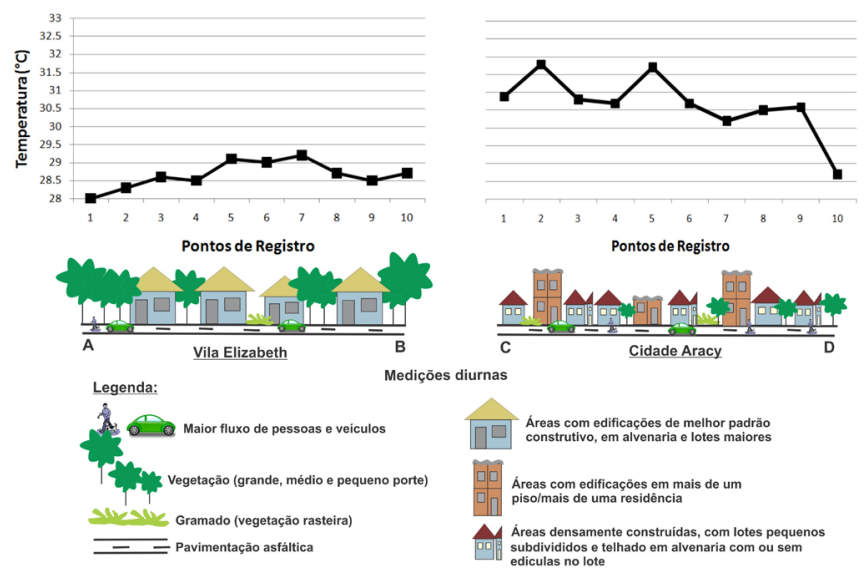

Figura 4. Perfil longitudinal da temperatura do ar às $15 \mathrm{hrs} \mathrm{em} \mathrm{São} \mathrm{Carlos.}$

Estas diferenças se evidenciam no perfil longitudinal do horário noturno (Figura 5), visto que toda a radiação absorvida e armazenada durante o dia pelos materiais construtivos é refletida para o ar na forma de calor sensível durante a noite.

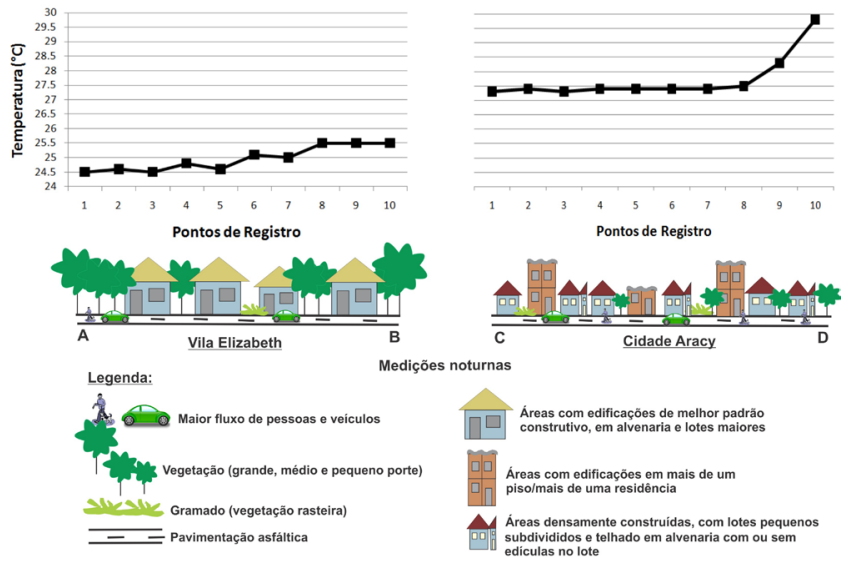

Figura 5. Perfil longitudinal da temperatura do ar às $18 \mathrm{hrs} \mathrm{em} \mathrm{São} \mathrm{Carlos.}$

O gradiente térmico foi de $5,3^{\circ} \mathrm{C}$, sendo a mínima de $24,5^{\circ} \mathrm{C}$ nos pontos 1 e 3 na Vila Elizabeth e a máxima de $29,8^{\circ} \mathrm{C}$ (ponto 10) na Cidade Aracy.

\section{Conclusão}

Os resultados mostram uma forte relação entre estes extremos de temperatura e a forma de organização dos espaços na cidade média tropical de São Carlos, ditada grande parte pelos interesses extremamente desiguais dos agentes produtores do espaço, a partir da seletividade das áreas. Assim, também o clima passa a refletir nas diferenças térmicas e desconforto ambiental a importância do planejamento urbano e adequação dos espaços de vivência da 
população não somente com vistas ao valor agregado do solo urbano. A perspectiva analítica do clima urbano é ampla, e atribuir-lhe um caráter social tal como propõe a Geografia do clima a partir da incorporação da produção desigual do espaço, vai além de sua dimensão da formal, atribuindo ao clima um caráter dialético.

\section{Bibliografia}

Amorim, M.C.C.T. (2011) - A Raia Divisória São Paulo - Paraná - Mato Grosso do Sul. São Paulo, Ed.Outras Expressões, p.[133-165];

Carlos, Ana Fani. A. (2007) - Diferenciação socioespacial. Revista Cidades, vol.(4, n. 6). 2007, p. [45-60];

Fernández García, F.; Rasilla álvarez, D., (2008) - Olas de calor e influencia urbana en Madrid y su área metropolitana. Heat waves in urban and suburban Madrid. Estudios Geográficos, LXIX, 265, juliodiciembre, p.[495-518];

Lima, Renata P. (2007) - O processo de (des) controle da expansão urbana de São Carlos. Dissertação de Mestrado em Arquitetura e Urbanismo. Universidade Federal de São Carlos. São Carlos. [193 p].

Lopes, António. (2009) - O sobreaquecimento das cidades causas e medidas para a mitigação da ilha de calor de lisboa. Revista Territorium, Revista da Associação Portuguesa de Riscos, Prevenção e Segurança,

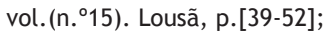

Monteiro, Ana. (1997) - O clima urbano do Porto: contribuição para a definição das estratégias de planejamento e ordenamento do território. Lisboa: Fundação Calouste Gulbekian, [ 486 p].

Sant'Anna Neto, J. L. (2011) - Por uma Geografia do Clima: antecedentes histórico, paradigmas contemporâneos e uma nova razão para um novo conhecimento. Revista Terra Livre. São Paulo, (n. ${ }^{\circ} 20,2^{\circ}$ semestre), p.[49-62].

Sant'Anna Neto, J. L., (2011/2012) - O clima como risco, as cidades como sistemas vulneráveis, a saúde como promoção da vida. Cadernos de Geografia. Coimbra, FLUC, n³0/31, [215-227].

Sposito, Maria Encarnação Beltrão. (2004) - 0 chão em pedaços: urbanização, economia e cidades no Estado de São Paulo. Presidente Prudente. [508 p].

Vilagrasa, Joan. (1991) - Estudio de la Morfologia urbana: uma aproximación. Revista Geocrítica, Barcelona, (n. ${ }^{\circ}$ 92, mar), p. [1-24]. 